\title{
TAM kinase signaling is indispensable for proper skeletal muscle regeneration in mice
}

\author{
Nour Al-Zaeed ${ }^{1}$, Zsófia Budai ${ }^{2}$, Zsuzsa Szondy iD $^{2,3,4}$ and Zsolt Sarang ${ }^{2,4}$
}

(c) The Author(s) 2021

Skeletal muscle regeneration following injury results from the proliferation and differentiation of myogenic stem cells, called satellite cells, located beneath the basal lamina of the muscle fibers. Infiltrating macrophages play an essential role in the process partly by clearing the necrotic cell debris, partly by producing cytokines that guide myogenesis. Infiltrating macrophages are at the beginning pro-inflammatory, but phagocytosis of dead cells induces a phenotypic change to become healing macrophages that regulate inflammation, myoblast fusion and growth, fibrosis, vascularization and return to homeostasis. The TAM receptor kinases Mer and Axl are known efferocytosis receptors in macrophages functioning in tolerogenic or inflammatory conditions, respectively. Here we investigated their involvement in the muscle regeneration process by studying the muscle repair following cardiotoxininduced injury in $\mathrm{Mer}^{-1-}$ mice. We found that Axl was the only TAM kinase receptor expressed on the protein level by skeletal muscle and C2C12 myoblast cells, while Mer was the dominant TAM kinase receptor in the CD45 ${ }^{+}$cells, and its expression significantly increased during repair. Mer ablation did not affect the skeletal muscle weight or structure, but following injury it resulted in a delay in the clearance of necrotic muscle cell debris, in the healing phenotype conversion of macrophages and consequently in a significant delay in the full muscle regeneration. Administration of the TAM kinase inhibitor BMS-777607 to wild type mice mimicked the effect of Mer ablation on the muscle regeneration process, but in addition, it resulted in a long-persisting necrotic area. Finally, in vitro inhibition of TAM kinase signaling in C2C12 myoblasts resulted in decreased viability and in impaired myotube growth. Our work identifies Axl as a survival and growth receptor in the mouse myoblasts, and reveals the contribution of TAM kinase-mediated signaling to the skeletal muscle regeneration both in macrophages and in myoblasts.

Cell Death and Disease (2021)12:611; https://doi.org/10.1038/s41419-021-03892-5

\section{INTRODUCTION}

Regeneration of the skeletal muscle following injury is an adaptive response of the organ. It involves many stages and the coordinated appearance and action of various cell types [1]. The regeneration process begins with degeneration of myofibers and infiltration of immune cells creating an inflammatory environment $[2,3]$. Later, the quiescent muscle stem cells (satellite cells (SCs)) are activated leading to their asymmetric cell division and differentiation into myoblasts that also proliferate and fuse together to form the new myofibers. In the last phase of myogenesis growth of new myofibers, angiogenesis and matrix remodeling take place [4].

During the initial inflammatory phase, neutrophils arrive with the first wave of cells followed by Ly6C high monocytes that differentiate into inflammatory Ly6C $\mathrm{C}^{\text {high }}$ macrophages (MФs). These cells play a critical role in orchestrating the muscle regeneration partly by phagocytosing the necrotic myofibers and dying neutrophils, partly by releasing various cytokines and growth factors. The initial inflammation creates an environment for the activation, proliferation, and differentiation of SCs, while the resolution of inflammation for the fusion of myoblasts and fiber growth $[1,5,6]$. The timed switch between the two main subsets of MФs, the Ly6C $C^{\text {high }}$ ones producing pro-inflammatory cytokines (e.g., tumor necrosis factor- $\alpha$ (TNF- $\alpha$ ), interleukin- $1 \beta$ (IL-1 $\beta)$, and interleukin-6 (IL-6)) and the healing Ly6C ${ }^{\text {low }}$ ones producing anti-inflammatory cytokines and growth factors (e.g., interleukin-10 (IL-10), transforming growth factor- $\beta$ (TGF- $\beta$ ), and growth differentiation factor-3 (GDF3)) [6-9], is a key to the proper regeneration process, and it is thought to be induced by the efferocytosis process [10]. Several transcriptional factors, such as Pax7 and MyoD, which regulate the expression of muscle tissuespecific genes (e.g., myosin heavy chain 1 (MYHC1)), and consequently the whole myogenesis [11-13], are under the control of $M \Phi$-derived cytokines that act in autocrine, paracrine, and endocrine manner to orchestrate the immune response as well as the myogenic program of SCs $[14,15]$.

The TAM receptors (Tyro3/Axl/Mer) form one of the families of tyrosine kinase receptors [16-19]. Mer tyrosine kinase (Mer), a member of this family, is expressed by megakaryocytes, platelets, endothelial cells, epithelial tissue, by the reproductive tissue, and by a broad range of immune cells [20], and is highly upregulated in MФs during M1-M2 transition [21]. In MФs, it participates in the GAS6- and protein S-dependent recognition of phosphatidylserine (PS) on the surface of dying cells and thereby facilitates the

\footnotetext{
${ }^{1}$ Doctoral School of Molecular Cell and Immune Biology, University of Debrecen, 1 Egyetem square, Debrecen H-4032, Hungary. ${ }^{2}$ Department of Biochemistry and Molecular Biology, Faculty of Medicine, University of Debrecen, 1 Egyetem square, Debrecen H-4032, Hungary. ${ }^{3}$ Dental Biochemistry, Faculty of Dentistry, University of Debrecen, 1 Egyetem square, Debrecen H-4032, Hungary. ${ }^{4}$ These authors contributed equally: Zsuzsa Szondy, Zsolt Sarang. Edited by G. Sorci. ${ }^{凶}$ email: szondy@med.unideb.hu
}

Received: 5 February 2021 Revised: 21 May 2021 Accepted: 24 May 2021

Published online: 12 June 2021 
phagocytic clearance of dead cells, resolution of inflammation, and dampening innate immune responses after acute injury [22-26]. The pathological effects of Mer deficiency were apparent in decreased clearance of apoptotic bodies and in the subsequently increased necrosis in diseases such as atherosclerosis and myocardial infarction [27-30]. Moreover, many in vivo and ex vivo studies demonstrated that Mer-deficient monocytes and MФs display increased inflammatory phenotype, as following activation, they produce larger amounts of pro-inflammatory and decreased amounts of anti-inflammatory cytokines [23, 25, 29]. In this study, we tested the hypothesis that by promoting efferocytosis and by regulating cytokine production $M \Phi$, Mer might be involved in the regeneration of injured muscle.

\section{MATERIALS AND METHODS \\ Reagents}

All reagents were obtained from Sigma-Aldrich (Budapest, Hungary), except when indicated otherwise.

\section{Experimental animals}

Experiments were carried out using 2-4-month-old full-body knockout $\mathrm{Mer}^{+/+}$and $\mathrm{Mer}^{-/-}$males and where it is indicated female mice. Mice were purchased from the Jackson Laboratory (Bar Harbor, Maine, USA) and bred in heterozygous form under specific pathogen-free conditions in the central animal facility of the University of Debrecen. All animal experiments were approved by the Animal Care and Use Committee of the University of Debrecen (DEMÁB) with a permission number 7/2016/DEMÁB.

\section{Cardiotoxin-induced muscle injury model}

Mice were anesthetized by intraperitoneal injection of pentobarbital $(80 \mathrm{mg} /$ $\mathrm{kg}$ mouse). After anesthesia, muscle injury was induced by injecting $50 \mu \mathrm{l}$ of $12 \mu \mathrm{M}$ cardiotoxin (CTX) (Latoxan, Valence, France) in phosphate-buffered saline (PBS) into the tibialis anterior (TA) muscle. The size of the control and treated groups was the same as reported by others in similar experiments [31]. There were no inclusion or exclusion criteria used in the selection of the animals. Animals from each cage were randomly allocated to the control or treated groups, but no blinding was used. Mice were sacrificed and muscles were harvested at various time points following injury. Samples were frozen for immunohistochemical staining or processed for Western blot analysis, cell, or mRNA isolation. In some experiments, $10 \mathrm{mg} / \mathrm{kg}$ body weight pan-TAM tyrosine kinase inhibitor BMS-777607 was injected intraperitoneally into wildtype mice on the first and third, or on the fifth, seventh, and ninth day of cardiotoxin injury.

\section{Isolation of muscle-derived $\mathrm{CD}^{+} 5^{+}$leukocytes and F4/80 MФs}

$\mathrm{CD}^{4} 5^{+}$leukocytes or $\mathrm{F} 4 / 80^{+} \mathrm{M \Phi s}$ were isolated from TA muscles using a modified protocol developed by Patsalos et al. [31]. For the phagocytosis experiments, muscle-derived MФs were suspended in Dulbecco's modified Eagle's medium (DMEM) supplemented with 10\% fetal bovine serum (FBS) (Invitrogen, Carlsbad, USA), penicillin (100 units/ml; Invitrogen, Carlsbad, USA), streptomycin ( $100 \mathrm{mg} / \mathrm{ml}$; Invitrogen, Carlsbad, USA), and $2 \mathrm{mM}$ L-glutamine and incubated in 12 -well plates $\left(3 \times 10^{5}\right.$ cells/well) for $48 \mathrm{~h}$ at $37^{\circ} \mathrm{C}$. After two days, floating cells were washed away, and fresh medium was added to the attached cells for an additional $24 \mathrm{~h}$.

\section{Quantification of intramuscular immune cells by flow cytometry}

The magnetically separated muscle-derived $\mathrm{CD}_{4} 5^{+}$cells were stained with a combination of Alexa Fluor 488-conjugated anti-F4/80 antibody (MF48020, Invitrogen, Carlsbad, USA) and Alexa Fluor 647 conjugated anti-Ly6G/Ly6C (GR-1) antibodies (108418, BioLegend, San Diego, USA) at room temperature for 15 minutes. Cells were gated based on their forward- and side-scatter characteristics. Macrophages were gated as GR-1 negative and F4/80 positive, while neutrophils as F4/80-negative and GR-1-positive cells. F4/80-positive macrophages were also analyzed for Ly6C, CD206 or MHCIl expressions following staining with Ly6C PerCP-Cy5.5 (128012, BioLegend, San Diego, USA), CD206-PE (141705, BioLegend, San Diego, USA) or MHCII-FITC (107605, BioLegend, San Diego, USA) antibodies, respectively. Fluorescent intensity was detected with a Becton Dickinson FACSCalibur instrument.

\section{Cell sorting}

The magnetically separated muscle-derived $\mathrm{CD} 45^{+}$cells were stained with a combination of Alexa Fluor 488-conjugated anti-F4/80 antibody and Ly6C PerCP-Cy5.5 antibodies at room temperature for 15 minutes. Macrophages were gated as $\mathrm{F} 4 / 80$ positive cells and further separated Ly6C high and Ly6C low populations based on their Ly6C expression level on BD FACSAria ${ }^{\mathrm{TM}}$ III Cell Sorter.

\section{Immunofluorescent staining and immunohistochemistry}

Muscles from control mice or at 2-, 4-, 10- or 22-day post injury were dissected for histological assessment. Muscles were snap-frozen in liquid nitrogen-cooled isopentane and kept at $-80^{\circ} \mathrm{C}$. About 7- $\mu \mathrm{m}$ cryosections were cut at $-20{ }^{\circ} \mathrm{C}$ using a 2800 Frigocut microtome (Leica, St Jouarre, France) and were kept at $-20^{\circ} \mathrm{C}$ until further analysis. Hematoxylin and eosin (H\&E) staining was performed to assess the overall morphology and the presence of necrotic fibers following injury. To calculate the crosssectional and collagen-stained areas, briefly frozen muscle sections were incubated $10 \mathrm{mM}$ citric acid-sodium citrate buffer ( $\mathrm{pH}$ 6.0) for $15 \mathrm{~min}$, then in blocking solution (50\% FBS in PBS) for $1 \mathrm{~h}$ at room temperature followed by the incubation of the muscle sections with Dylight 488-conjugated antilaminin B (PA5-22901,Invitrogen, Carlsbad, USA) (1:100), or anti-collagen 1 antibody (SAB4500362) $(1: 100)$ at $4{ }^{\circ} \mathrm{C}$ overnight followed by Alexa Fluor 488-conjugated goat anti-rabbit IgG secondary antibody. Slides were counterstained with $4 \mu \mathrm{g} / \mathrm{ml}$ 4',6-diamidino-2-phenylindole (DAPI) (Invitrogen, Carlsbad, USA). Images were analyzed using ImageJ software (National Institutes of Health, Bethesda, USA) with muscle morphometry plugin. Areas with fibers containing centrally-located nuclei were considered as regenerating muscle parts. CSAs are reported in $\mu \mathrm{m}^{2}$, while the amount of collagen deposition as percent of the total examined regenerating area. For MYHC4 staining $\mathrm{C} 2 \mathrm{C} 12$ cells were fixed with ice-cold methanol and washed three times with PBS, blocked with PBS/2\% BSA $1 \%$ Tween20 for $1 \mathrm{~h}$. Alexa fluor488-conjugated anti-MYHC4 (53-6503-82, Invitrogen, Carlsbad, USA) was added at 1:100 dilution for $24 \mathrm{~h}$ at $4{ }^{\circ} \mathrm{C}$. For phosphorylated $\mathrm{S} 10$, histone $\mathrm{H} 3$ staining rabbit polyclonal anti-Histone $\mathrm{H} 3$ (phospho S10) antibody (ab5176, Abcam, Cambridge, UK) was added at 1:4000 dilution for $1 \mathrm{~h}$ at room temperature. After washing three times with PBS, cells were labeled with MACH 2 Anti-Rabbit HRP-Secondary Polymer solution (RHRP520, Biocare Medical, Pacheco, USA) and counterstained with DAPI. Pictures were taken on a fluorescent microscope (FLoid $^{\text {TM }}$ Cell Imaging Station).

\section{C2C12 cell culture and differentiation}

Murine myoblast C2C12 cell line was obtained from ATCC (CRL-1772) and cells were maintained according to the company's instructions. In brief, cells were cultured in DMEM supplemented with $10 \% \mathrm{FBS}, 100 \mathrm{U} / \mathrm{ml}$ penicillin, and $100 \mu \mathrm{g} / \mathrm{ml}$ streptomycin (growth medium) at $37^{\circ} \mathrm{C}$ in $5 \%$ CO2 and $95 \%$ air at $100 \%$ humidity. The absence of mycoplasma was tested using PCR Mycoplasma Test Kit I/C (PromoCell, Heidelberg, Germany). For gene expression analysis cells were plated into 24-well plates, while for immunofluorescent staining into 96 -well plates at a density of 3500 cells $/ \mathrm{cm}^{2}$. For the 6-day differentiation period, DMEM medium containing 2\% FBS and 1\% ITS (insulin, transferrin, and sodium selenite) (low serum differentiation medium) was used and replaced every $2^{\text {nd }}$ day with fresh one. In some cases, $1 \mu$ M BMS-777607 was added to the wells. To evaluate myoblast fusion, cells were stained with MYHC4 antibody and DAPI, as described previously. Digitally captured photos were taken and analyzed using ImageJ software. The fusion index was calculated by expressing the number of nuclei within MYHC4-positive myotubes with $\geq 3$ nuclei as percentage of the total nuclei $(n=500)$, additionally the length of fibers was measured. Viable cell number was assessed using PrestoBlue (ThermoFisher, Waltham, USA) staining according to the manufacturer's instructions. Fluorescence was measured on Synergy ${ }^{\mathrm{TM}}$ $\mathrm{H} 1$ microplate reader. Dying cells in culture were labeled with propidium iodide $(80 \mu \mathrm{g} / \mathrm{ml})$ for $5 \mathrm{~min}$, while total cell number was determined by DAPI staining.

\section{Gene expression analysis}

RNA from magnetically separated muscle-derived $\mathrm{F} 40 / 80^{+}, \mathrm{CD}_{4} 5^{+}$and $\mathrm{C} 2 \mathrm{C} 12$ cells, and total TA muscles, was isolated with TRIzol (Invitrogen, Carlsbad, USA) reagent according to the manufacturer's instructions. Mer ${ }^{+/+}$and ${ }^{-/-}$control and regenerating TA muscles were homogenized in TRIzol using a Shakeman homogenizer (BioMedical Science, USA). Total RNA was isolated by using the TRI reagent according to the manufacturer's guidelines (ThermoFisher, 
Waltham, MA, USA). Total RNA was reverse-transcribed into cDNA using a High Capacity cDNA Reverse Transcription Kit (Life Technologies, Budapest, Hungary) according to the manufacturer's instruction. qRT-PCR was carried out in triplicates using predesigned FAM-labeled MGB assays (Life Technologies, Budapest, Hungary), including LightCycler 480 Multiwell 384 white plates sealed with adhesive tapes on a Roche LightCycler LC 480 realtime PCR instrument. Relative mRNA levels were calculated using the comparative CT method and were normalized to $\beta$-actin mRNA. In case of the total muscle samples, gene expressions were normalized to the total RNA content $(200 \mathrm{ng})$ of the samples. Catalog numbers of the TaqMan assays used were the following: Actb Mm02619580_g1, Itgb1 Mm01253230_m1, Tgfb1 Mm01178820_m1, Myod1 Mm00440387_m1, Myhc1 Mm01332489_m1, Myog Mm00446194_m1, Tnf Mm00443258_m1, Gdf3 Mm00433563_m1, IL1B Mm00434228_m1, IL10 Mm01288386_m1, IL6 Mm00446190_m1, Arg1 Mm00475988_m1, Mer Mm00434920_m1, Axl Mm00437221_m1, Tyro3 Mm00444547_m1, Pax7 Mm00834082_m1.

\section{Western blot analysis}

For detecting MYHC4, Mer, Tyro3, or Axl protein expression in the differentiating $\mathrm{C} 2 \mathrm{C} 12$ cells or in wild-type muscles, the whole-cell homogenate was used. The homogenates were prepared in ice-cold lysis buffer (10\% v/v glycerol, 1\% v/v Triton X-100, 1 mM EGTA, $20 \mathrm{mM}$ Tris, $\mathrm{pH}$ 7.9, $100 \mu \mathrm{M}$ ß-glycerophosphate, $137 \mathrm{mM} \mathrm{NaCl}, 5 \mathrm{mM}$ EDTA, $1.04 \mathrm{mM}$ AEBSF, $0.8 \mu \mathrm{M}$ aprotinin, $40 \mu \mathrm{M}$ bestatin, $14 \mu \mathrm{M}$ E-64, $20 \mu \mathrm{M}$ leupeptin, and $15 \mu \mathrm{M}$ pepstatin A). The protein content of the samples was determined by Bio-Rad Protein Assay Dye (Bio-Rad, Budapest, Hungary), and then the homogenate was boiled in a loading buffer with an aliquot corresponding to $40 \mu \mathrm{g}$ of protein. Proteins were run on a polyacrylamide gel and blotted onto polyvinylidene difluoride membranes using the Bio-Rad electrophoresis and transfer system. Proteins were visualized by anti-MYHC4 (cat\#: 536503-82), anti-Mer (cat\#: 16-5751-85), anti Tyro3 (cat\#: PA5-14737), or antiAxI (cat\#: PA5-106118) (all from Invitrogen, Carlsbad, USA) antibodies. Equal loading of proteins was demonstrated by probing the membranes with anti-a tubulin (sc-5286, Santa Cruz Biotechnology, Dallas, USA) antibodies.

\section{In vitro phagocytosis assay}

Phagocytosis assay was performed as described previously [32]. Briefly, target $\mathrm{C} 2 \mathrm{C} 12$ cell necrosis was induced by heating the cells for 10 minutes at $65{ }^{\circ} \mathrm{C}$. C2C12 cells were stained with $1 \mu \mathrm{M}$ CellTracker Deep Red Dye (ThermoFisher, Waltham, USA) and added to MФs at 5:1 ratio (dead cell/ $M \Phi)$. After 1-h co-culture, target cells were washed away extensively and MФs were detached by EDTA. MФs were labeled with Alexa Fluor 488conjugated anti-F4/80 antibody (Invitrogen, Carlsbad, USA) for $20 \mathrm{~min}$ and the percentage of engulfing cells was determined on a Becton Dickinson FACSCalibur flow cytometer.

\section{Quantification of necrotic areas}

Areas of necrosis were identified based on the following histological criteria: blurring of cell borders, cytoplasmic fragmentation, caliber variation, cell distances, loss of nuclei, and increased immune cell infiltration. Necrotic myofibers were defined as pink pale patchy fibers that are infiltrated by basophil single cells and quantified as described previously [33]. Briefly, 4 nonoverlapping microscope view field areas were digitally captured from 6-8 H\&E-stained TA muscle sections at 200-fold magnification. The percentage of necrotic area/total regenerating area was calculated after the manual outlining the necrotic fibers in the sections.

\section{Statistical analysis}

All the data are representative of at least three independent experiments and all data are expressed as mean or median \pm SEM. Statistical analysis was performed using two-tailed, unpaired Student's $t$-test and ANOVA with post hoc Tukey HSD test. The equal variance of the samples was tested by F-test. ${ }^{*}$ indicates $p<0.05,{ }^{* *}$ indicates $p<0.01$.

\section{RESULTS}

Mer deficiency impairs TA muscle regeneration

To study a possible role of Mer in muscle homeostasis and regeneration, we compared the muscle weights and the myofiber CSAs of vehicle- and CTX- treated TA muscles from $\mathrm{Mer}^{+/+}$and $\mathrm{Mer}^{-1-}$ mice. There was no significant difference between the body weight of $\mathrm{Mer}^{+/+}$and $\mathrm{Mer}^{-/-}$mice (data not shown). TA muscle weights were also not different between control and regenerating muscles at day 10 and 22 post injury in $\mathrm{Mer}^{-/-}$mice as compared to the wild-type controls (Fig. 1a).

There was also no difference in the fiber size between $\mathrm{Mer}^{+/+}$ and $\mathrm{Mer}^{-1-}$ muscles before injury, but the mean and median CSA of newly formed myofibers with central nuclei in $\mathrm{Mer}^{-1-}$ mice were significantly smaller than in $\mathrm{Mer}^{+/+}$mice at day 10 and 22 post injury (Fig. 1b). The CSA frequency distribution showed similar fiber size distribution in control $\mathrm{Mer}^{+/+}$and ${ }^{-/-}$mice, but the frequency of smaller fibers was higher, while that of bigger fibers was lower in regenerating $\mathrm{Mer}^{-/-}$muscles as compared to wild type ones (Fig. 1c).

The number of myofibers with two or more central nuclei is an indicator of myoblast fusion in the regenerating muscles. The number of newly formed fibers with two or more central nuclei was decreased in $\mathrm{Mer}^{-1-}$ mice as compared to wild type mice at day 10 post injury, but this difference disappeared by day 22 post injury (Fig. 1d). These preliminary data indicated a delay in the skeletal muscle regeneration in the absence of Mer.

Since previous studies indicated that female hormones affect the muscle regeneration process [34], we repeated these experiments with female mice as well (Fig. S1). We could confirm generally a smaller muscle cross-sectional area in female muscles, but found similar alterations in the Mer null female muscle regeneration that we observed in males.

\section{Delayed differentiation of satellite cells after injury in the absence of Mer}

To assess the involvement of Mer in muscle regeneration, the mRNA levels of TAM kinases, that of myogenic genes, such as Pax7 and the MyoD transcription factors involved in SC proliferation and differentiation, as well as that of the myosin heavy chain 1 (MYHC1), a myoblast differentiation marker, were examined in the control and regenerating TA muscles. Additionally, the protein expression levels of the skeletal muscle Mer, Axl, and Tyro3 were also determined.

The mRNA levels of Pax7, the SC-specific transcription factor, were strongly induced by day 4, and loss of Mer did not affect this induction (Fig. 2a). However, the expression of MyoD was lower in the muscles of $\mathrm{Mer}^{-1-}$ mice as compared to wild-type ones at days 2 and 4 after CTX-induced muscle injury, while that of MYHC1 was lower in $\mathrm{Mer}^{-/-}$mice compared with $\mathrm{Mer}^{+/+}$mice at day 10 post injury indicating a delayed differentiation (Fig. 2a). Among the TAM kinases Axl mRNA was dominantly expressed by the skeletal muscle, and its expressions showed a similar pattern to that of Pax7 during muscle regeneration (Fig. 2b). Similar to Pax7, loss of Mer did not affect the expression of Axl either. In accordance with the mRNA data, we could detect only the expression of $\mathrm{Axl}$ on protein level in the mouse skeletal muscle (Fig. 2c) similar to human studies, which also demonstrated that Axl is the dominant TAM kinase expressed by skeletal muscle cells (https://www.proteinatlas.org). These findings indicate that not the SCs or myoblasts are the cells, where loss of Mer might primarily affect muscle regeneration.

\section{Normal recruitment of $M \Phi s$ and neutrophils after injury in the absence of Mer}

Since Mer is involved in the phagocytosis of both apoptotic and necrotic cells by macrophages [32], and altered efferocytosis might affect the muscle regeneration program [10], our interest turned to the inflammatory cells. Migration of inflammatory cells to the injured area and tissue inflammation plays a crucial role in the muscle regeneration process following injury. To assess the composition of leukocytes in the early phase of muscle regeneration, we performed flow cytometric analysis of magnetically separated $\mathrm{CD}_{4} 5^{+}$cells from collagenase-digested muscles (Fig. S2a). In accordance with previous observations, we detected early 

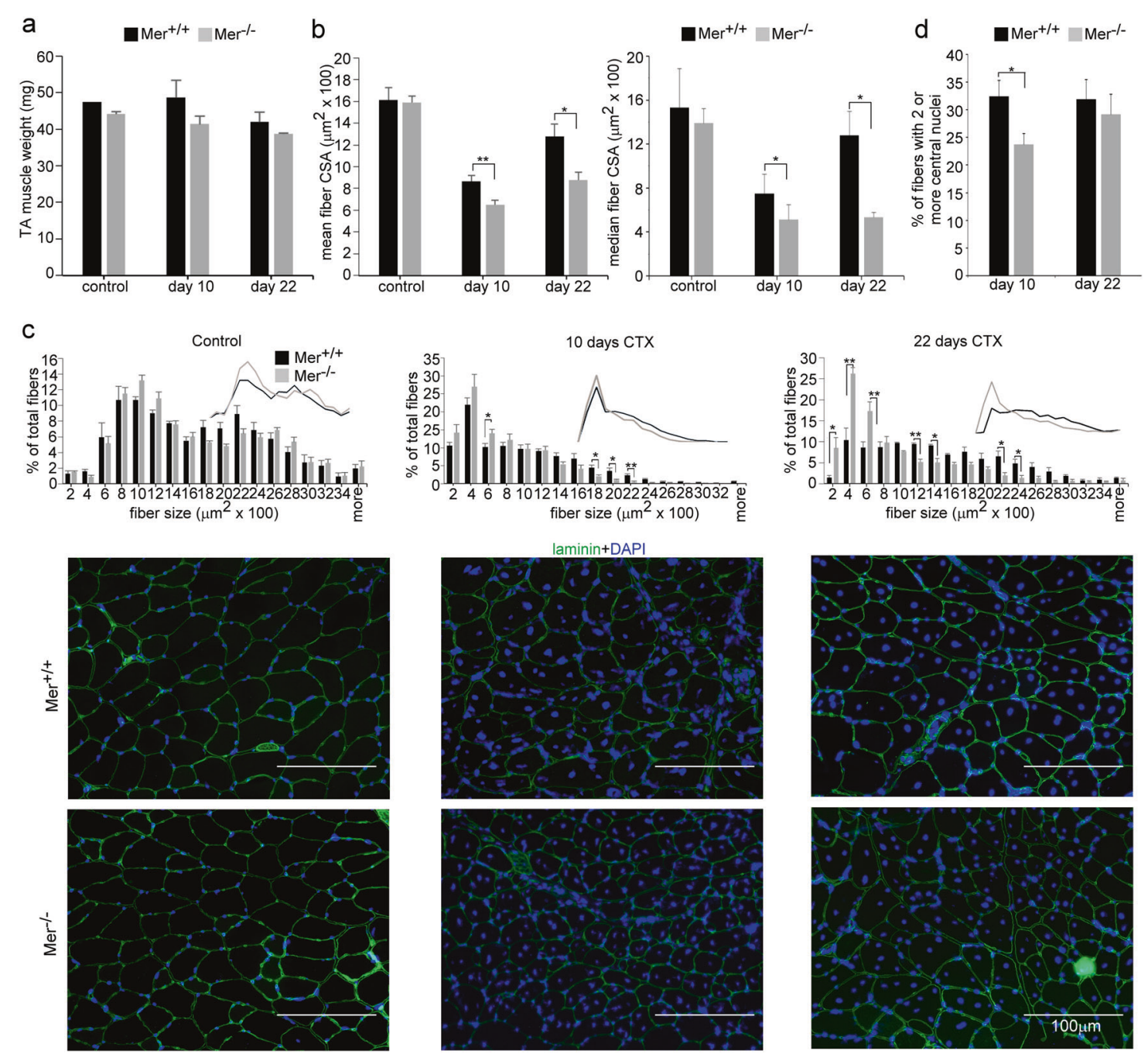

Fig. 1 Muscle regeneration is impaired in $\mathrm{Mer}^{-1-}$ mice. Muscle injury was induced by injecting $50 \mu \mathrm{l}$ of $12 \mu \mathrm{M}$ cardiotoxin (CTX) into the
tibialis anterior (TA) muscle of $\mathrm{Mer}^{+/+}$and $\mathrm{Mer}^{-/-}$mice. a Muscle weights, b mean and median myofiber cross-sectional areas (CSA), and tibialis anterior (TA) muscle of $\mathrm{Mer}^{+/+}$and Mer ${ }^{-/-}$mice. a Muscle weights, $\mathbf{b}$ mean and median myofiber cross-sectional areas (CSA), and
c distribution of myofiber sizes in control TA muscles of $\mathrm{Mer}^{+/+}$and $\mathrm{Mer}^{-\prime-}$ male mice, and at day 10 and 22 post-CTX-induced injury together with their representative immunofluorescence images of laminin (green) and DAPI (blue) nuclear staining. Scale bars, $100 \mu \mathrm{m}$. In total, 500 or more myofibers were analyzed in each sample using ImageJ software. Data are expressed as mean or median \pm SEM. d Percentage of newly formed myofibers containing two or more central nuclei in TA muscles of Mer ${ }^{+/+}$and Mer ${ }^{-/-}$mice at day 10 and 22 post-CTX-induced injury. Data are expressed as mean $\pm \operatorname{SEM}(n=6)$. Asterisks indicate statistical significance $\left({ }^{*} P<0.05\right.$, Student's $t$-test).

infiltration of neutrophils at day 2 post injury followed by increasing numbers of $M \Phi$ s at days 3 and 4 in wild-type mice. Loss of Mer did not affect the number of infiltrating $\mathrm{CD}^{+} 5^{+}$cells (Fig. 3a), the neutrophil/MФ ratios (Fig. 3b), or the level of monocyte chemoattractant protein-1 (MCP-1), the main chemoattractant signal for $M \Phi$ recruitment [35] (Fig. 3c) in the regenerating muscle.

\section{Decreased phagocytic capacity of MФs and lower IL-10 and GDF3 expression in muscle-derived $\mathrm{CD}^{+}{ }^{+}$leukocytes in the absence of Mer}

We also determined the mRNA expression of Mer and various cytokines in the $\mathrm{CD}_{4} 5^{+}$cells. We found that early infiltrating wildtype $\mathrm{CD}_{4} 5^{+}$cells expressed Mer, and the M2- specific Mer expression was significantly induced by day 4 (Fig. 3d) in accordance with the formation of the M2-like Ly6Clow healing MФs on this day (Fig. 3e). Surprisingly, however, when we separated the Ly6C $C^{\text {high }}$ and the Ly6C ${ }^{\text {low }} \mathrm{F} 4 / 80^{+}$MФs (Fig. S2b), we found that Mer mRNA expression was induced with time in both populations (Fig. 3f), and the expression of it did not show a correlation with the Ly6C expression, despite the fact that the pro-inflammatory $\mathrm{IL}-1 \beta$, or TNF- $\alpha$ productions were associated with the Ly6Chigh pro-inflammatory population (Fig. 3f), as reported [6-9]. Efferocytosis of cell debris followed by a switch from a pro-inflammatory to an anti-inflammatory environment plays a key role during skeletal muscle regeneration. Fortifying the importance of Mer in dead cell engulfment, $\mathrm{Mer}^{-/-}$musclederived $\mathrm{F} 4 / 80^{+} \mathrm{M \Phi s}$ isolated at day 4 post injury displayed significantly lower necrotic myoblast phagocytic capacity than the wild-type ones (Fig. 3g).

During muscle regeneration the M1-specific IL-1 $\beta$, TNF- $\alpha$, and IL- 6 expression decreased, while the M2-specific TGF $\beta$ and GDF3 expression of $\mathrm{CD} 45^{+}$leukocytes increased in time in both strains. However, we found a significantly higher expression of IL-6, and significantly lower M2-specific TGF $\beta$ and GDF3 expression in the $\mathrm{Mer}^{-1-} \mathrm{CD}^{+} 5^{+}$leukocytes, as compared to the wild-type ones (Fig. 3h).

Delayed pro-inflammatory/healing phenotypic switch in Mer null macrophages during the muscle regeneration process

Since the data above suggested that Mer null MФs might have an altered pro-inflammatory/healing phenotypic switch during 
a
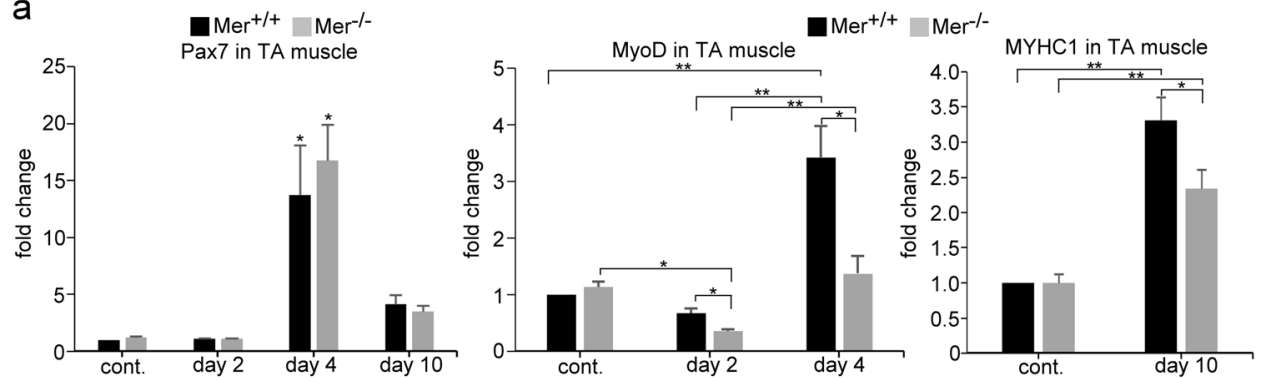

b

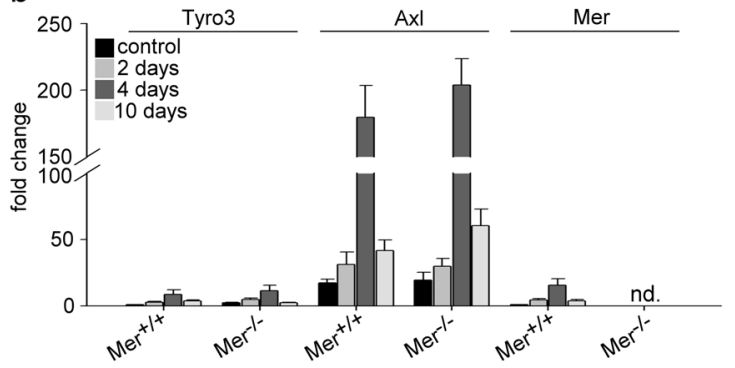

C
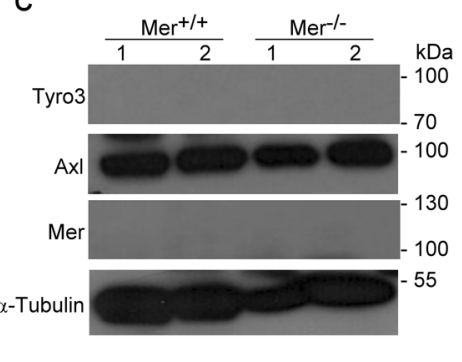

Fig. 2 Expression of TAM kinase family members and myogenic genes in the TA muscle of wild type and Mer null mice. a mRNA expressions of myogenic marker genes Pax7, MyoD and MYHC1 in control and in regenerating wild type and Mer null TA muscles determined by qRT-PCR at day 2, 4, or 10 post-CTX-induced injury. $\mathbf{b}$ mRNA expression levels of Mer, Axl and Tyro3 in control and in regenerating wild type and Mer null TA muscles determined by qRT-PCR at day 2, 4, or 10 post-CTX-induced injury. c Protein levels of Mer, Axl, and Tyro3 in the TA muscle of wild-type and Mer null mice determined by Western blot analysis. $\alpha$ Tubulin was used as a loading control. Data are expressed as mean $\pm \operatorname{SEM}(n=3)$. Asterisks indicate statistical significance $\left({ }^{*} P<0.05,{ }^{* *} P<0.01\right.$, ANOVA test).

muscle regeneration, we followed the phenotypic changes of MФs in both $\mathrm{Mer}^{+/+}$and $\mathrm{Mer}^{-1-}$ regenerating muscles. As seen in Fig. 3e, detected at day 3 , there was a delay in the disappearance of M1-specific [6-9] Ly6C high and in the appearance of M2-specific CD206 phagocytic receptor [36] expressing F4/80 ${ }^{+} \mathrm{M \Phi s}$ in $\mathrm{Mer}^{-/-}$ muscles. However, this difference disappeared by day 4. Similarly, a significant delay was observed in the appearance of $\mathrm{MHCII}^{\text {high }}$ expressing $\mathrm{Mer}^{-1-} \mathrm{F} 4 / 80^{+} \mathrm{M \Phi s}$ [37] as well (Fig. 3i). In addition, when $\mathrm{F} 4 / 80^{+} \mathrm{M \Phi s}$ were separated from regenerating muscles at day 4 post injury and analyzed for various M2 marker expressions, all the checked M2 markers were expressed at a lower amount by Mer null cells (Fig. 3j).

\section{Mer $^{-1-}$ TA muscles display delayed tissue repair and enhanced collagen deposition}

Since our data indicated impaired efferocytosis leading to delayed phenotypic switch of muscle MФs, we thought to determine also the rate of in vivo clearance by comparing the disappearance of necrotic fibers in wild-type and $\mathrm{Mer}^{-1-}$ muscles following CTX injection (Fig. 4a). As compared to the control tissue sections, during the first 2 days of injury, $\mathrm{Mer}^{+/+}$and $\mathrm{Mer}^{-1-}$ muscles displayed local necrosis and abundant inflammatory cell infiltration. At day 4 post injection, still large numbers of leukocytes and necrotic muscle fibers were visible in the injured muscles of both mouse strains. However, by day 10, in wild-type muscles, most of the necrotic fibers were cleared, while $\mathrm{Mer}^{-1-}$ muscles still contained significant amounts of necrotic areas at this time point (Fig. 4a). The percentages of necrotic areas were $7.33+-2.65$ and $18.22+-3.86$ in $\mathrm{Mer}^{+/+}$and $\mathrm{Mer}^{-/-}$muscles, respectively $(P<$ $0.01, n=3$ ). However, at day 22 post injury, the overall histological architecture of both $\mathrm{Mer}^{+/+}$and $\mathrm{Mer}^{-1-}$ muscles was restored, and necrotic fibers were no longer visible.

In addition to inflammatory macrophages and SCs, efficient muscle repair also requires the migration and proliferation of fibroblasts in order to produce new temporary extracellular matrix components. These elements serve to stabilize the tissue and act as a scaffold for the new fibers. In accordance, we detected an increased amount of collagen I in the regenerating muscles of both $\mathrm{Mer}^{+/+}$and $\mathrm{Mer}^{-/-}$mice as compared to their own non-regenerating muscles with a significantly higher collagen deposition in the case of $\mathrm{Mer}^{-1-}$ muscles at both days 10 and 22 post-injury (Fig. 4b).

\section{In vivo inhibition of TAM tyrosine kinase receptors impairs muscle regeneration}

To confirm that the observed impaired muscle regeneration in the Mer-knockout mice is indeed the consequence of a decreased TAM signaling in the muscle $M \Phi s$, and not the consequences of an offtarget mutation in the knockout strain, we injected the pan-TAM tyrosine kinase inhibitor BMS-777607 into wild-type mice during the first 5 days of CTX -induced injury (Fig. 5) and checked the regeneration process 5 days later at day 10 post injury. In harmony with the findings in Mer null mice, we found that the mean and median CSA of newly formed fibers was significantly lower, the frequency of smaller fibers was higher, while that of bigger fibers was lower in regenerating muscles of BMS-777607-treated $\mathrm{Mer}^{+/+}$mice as compared to vehicle-treated ones (Fig. $5 a-d$ ). The number of newly formed fibers with two or more central nuclei was also decreased in the BMS-777607-treated $\mathrm{Mer}^{+/+}$regenerating muscles as compared to that of the vehicle-treated ones at day 10 post injury (Fig. 5e). Similarly, the collagen deposition (Fig. 5f) and necrosis (Fig. $5 \mathrm{~g}$ ) were also significantly higher in the inhibitor-treated mice as compared to vehicle-treated ones. What is more, none of the results were significantly different, when compared to that of the Mer null mice, with the exception of the size of the necrotic area. This later was significantly larger in the inhibitor-treated mice indicating delayed clearance as compared to the Mer null mice. Accordingly, inhibition of TAM receptor kinases by BMS-777607 further inhibited efferocytosis by muscle $\mathrm{Mer}^{-1-}$ MФs (Fig. 5h). Since Tyro3 is not significantly expressed by MФs [38], we determined the mRNA expression of $\mathrm{Axl}$ in the $\mathrm{CD} 45^{+}$leukocyte population in which only macrophages express Axl. As shown in Fig. 5i, Axl was indeed expressed by $\mathrm{CD} 45^{+}$leukocytes, but its expression only slightly increased with time, as the macrophages started dominating the CD45 ${ }^{+}$leukocyte population. Addition of BMS-777607 also induced a delay in the macrophage phenotypic switch of MФs, but not more 

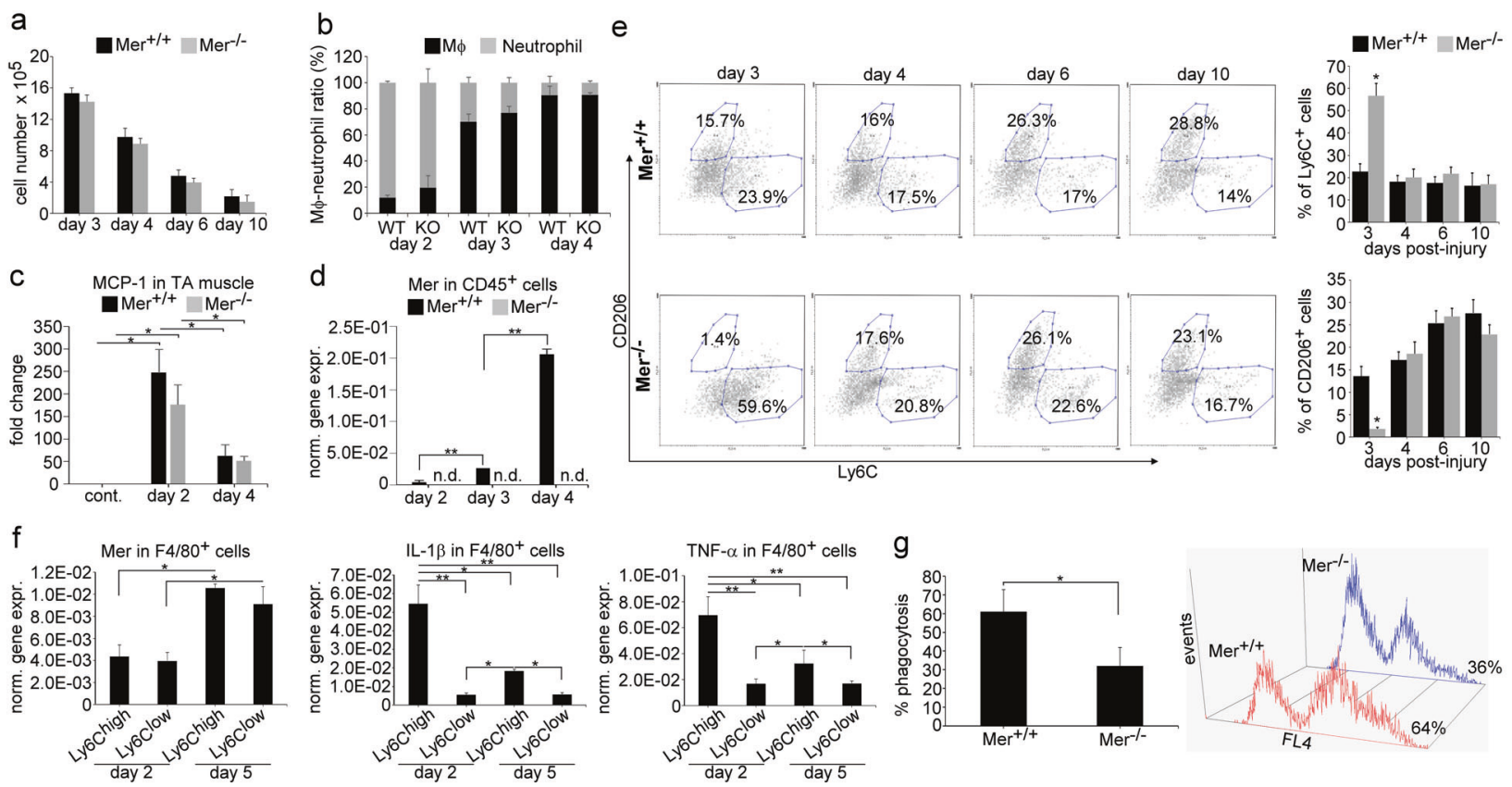

$\mathrm{h}$
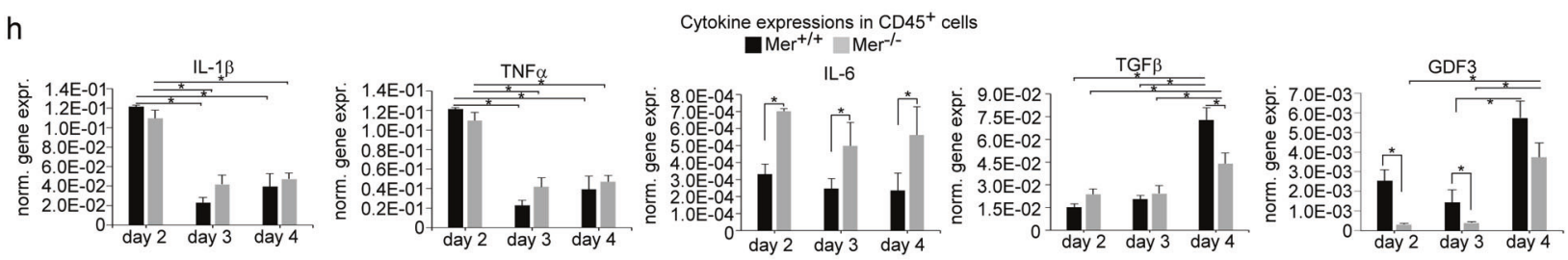

i
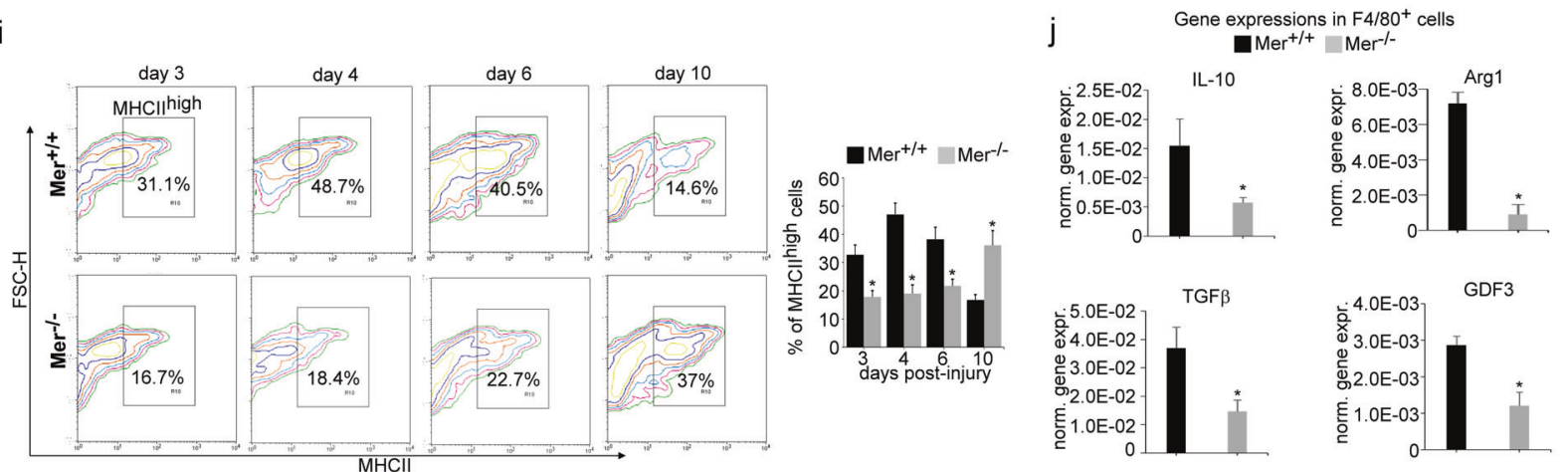

Fig. 3 As compared to wild-type mice, leukocyte infiltration is not altered in Mer null regenerating TA muscles following cardiotoxin injury, but the pro-inflammatory to healing phenotypic conversion of macrophages is delayed. Alterations a in the number of $C D 45^{+}$ leukocytes per injured muscle, b ratio of anti-F4/80 antibody-stained MФs and anti-Ly6G/Ly6C- (GR-1) stained neutrophils within the CD45 ${ }^{+}$ leukocyte population in $\mathrm{Mer}^{+/+}$and $\mathrm{Mer}^{-1-}$ TA muscles during the first 4 days of regeneration following CTX-induced injury $(n=3)$. c MCP-1 mRNA expression levels of muscle-derived wild type or Mer null CD45 leukocytes determined by qRT-PCR following CTX-induced injury $(n=$ 3). d Changes in Mer mRNA expressions of $C D 45^{+}$infiltrating leukocytes isolated from $\mathrm{Mer}^{+/+}$and Mer ${ }^{-/-}$regenerating TA muscles following CTX injury determined by qRT-PCR at the indicated time points $(n=6)$. e Representative scatter plots of CD206- and Ly6C-stained musclederived $\mathrm{F} 4 / 80^{+}$cells determined at the indicated days following CTX-induced injury $(n=3)$. $\mathbf{f}$ Mer, IL- $1 \beta$, and TNF- $\alpha$ mRNA expressions in Ly6C ${ }^{\text {high }}$ and Ly6C ${ }^{\text {low }} \mathrm{F} 4 / 80^{+}$cells isolated from TA muscles determined by qRT-PCR at days 2 and 5 post injury ( $n=3$ ). g Necrotic C2C12 myoblast cell phagocytic capacity of muscle-derived $\mathrm{Mer}^{+/+}$and $\mathrm{Mer}^{-/-} \mathrm{M} \Phi \mathrm{s}(\mathrm{MM} \Phi)$ isolated at day 4 post-CTX-induced injury determined by flow cytometric analysis $(n=3)$. $\mathbf{h}$ Changes in the mRNA expressions of the indicated cytokines in CD45 $5^{+}$infiltrating leukocytes isolated from $\mathrm{Mer}^{+/+}$and $\mathrm{Mer}^{-/-}$regenerating TA muscles following CTX-induced injury determined by qRT-PCR $(n=6)$. i Representative scatter plots of

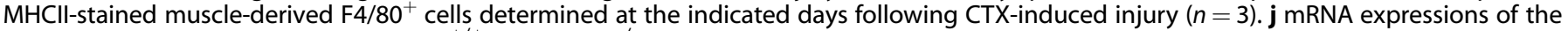
indicated M2 phenotypic markers in $\mathrm{Mer}^{+/+}$and in $\mathrm{Mer}^{-1-}$ muscle-derived MФs isolated at day 4 post CTX-induced injury determined by qRTPCR $(n=6)$. All data are expressed as mean \pm SEM. Asterisks indicate statistical significance $\left({ }^{*} P<0.05\right.$, ${ }^{* *} P<0.01$, Student's $t$-test and ANOVA test).

than the loss of Mer alone demonstrated by the delayed appearance of $\mathrm{MHCl}^{\text {high }}$ cells (Fig. 5j).

Similar experiments by injecting BMS-777607 on the fifth, seventh and ninth days did not affect the muscle regeneration process detected at day 10 post injury (Fig. S3b). These observations indicate that Mer and possibly Axl are required during the first days of the skeletal muscle regeneration process. Since loss of Mer results in a delay of the phenotypic change of macrophages leading to a delayed muscle regeneration, but additional inhibition of Axl by BMS-777607 did not 


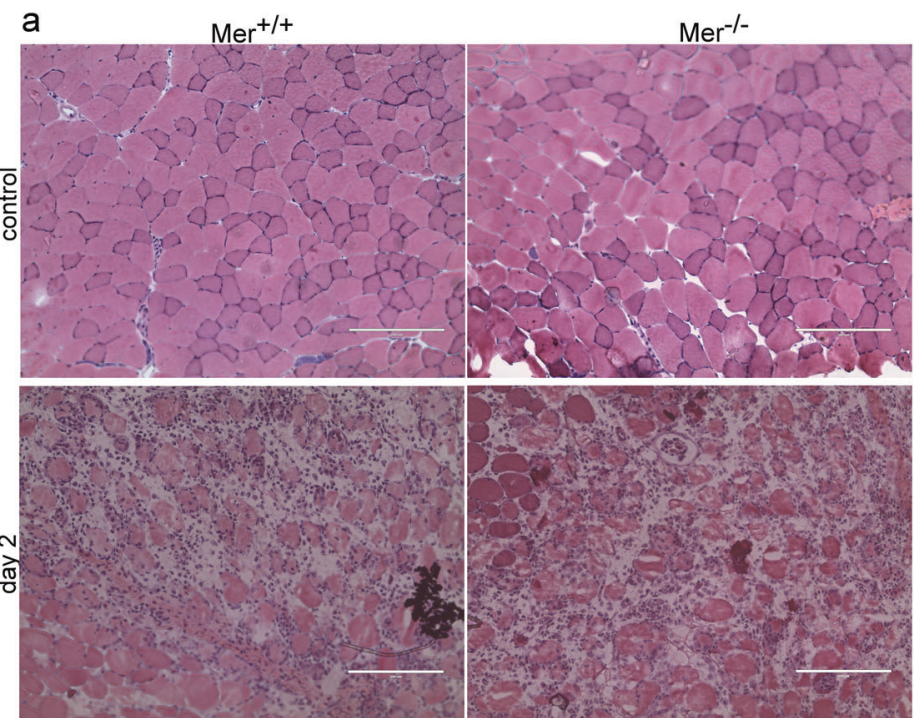

b collagen $1+$ DAPI
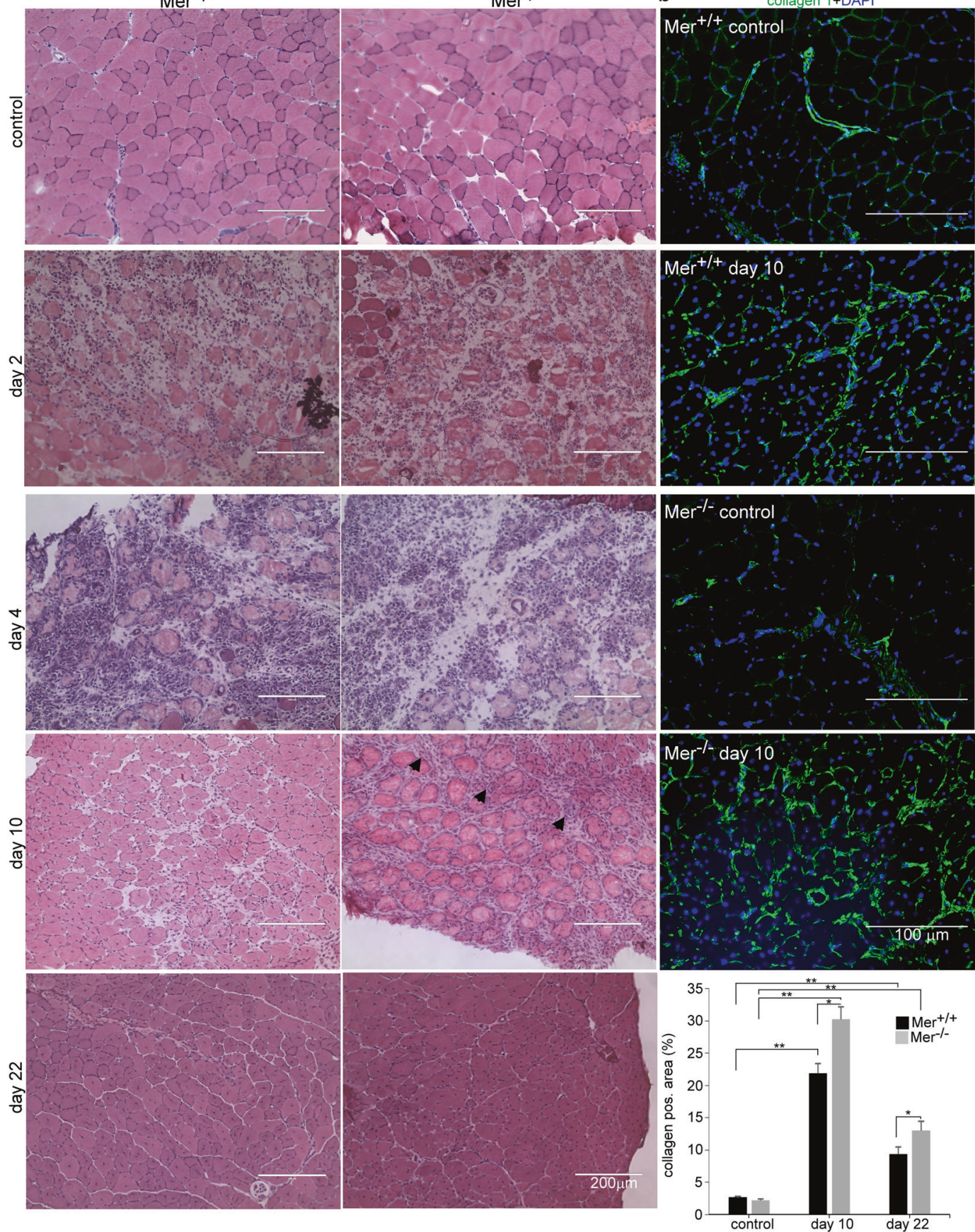

Fig. 4 Time-dependent histological morphology and collagen deposition of TA muscles following cardiotoxin-induced injury in Mer ${ }^{+\prime+}$ and $\mathrm{Mer}^{-1-}$ mice. a Representative H\&E stained cross-sections of $\mathrm{Mer}^{+/+}$and $\mathrm{Mer}^{-1-}$ TA muscles without treatment and at 2, 4, 10 and 22 post CTX-induced injury $(n=4$, except at day 10, when $n=6)$. Arrows indicate necrotic areas. Scale bars, $200 \mu \mathrm{m}$. b Representative immunofluorescence images of type 1 collagen (green) and DAPI (blue) nuclear staining in control and in Mer ${ }^{+/+}$and Mer ${ }^{-1-}$ TA muscles $^{-1}$ regenerating for 10 days, and quantification of collagen 1-positive areas in the control and in the regenerating muscles of Mer ${ }^{+/+}$and Mer ${ }^{-/-}$ mice at days 10 and 22 post CTX-induced injury. All data are expressed as mean \pm SEM ( $n=4$ in controls and $n=6$ in the CTX-treated muscles). Asterisks indicate statistical significance $\left({ }^{*} P<0.05,{ }^{*} P<0.01\right.$, ANOVA test).

induce a further delay in the regeneration, our data suggest that though AxI might contribute to the clearance by MФs, Mer drives dominantly the inflammatory to repair phenotype transition of macrophages and consequently the release of those macrophage-derived growth factors that drive myogenesis. In addition, because Axl is also expressed by muscle cells, we could not exclude that BMS-777607 could also affect the early proliferating and differentiating myoblasts contributing to the larger necrotic areas observed at day 10 of regeneration in inhibitor-treated muscles.

\section{Axl is a myotube growth and survival receptor for the $\mathrm{C} 2 \mathrm{C} 12$ myoblasts}

Shifting mouse $\mathrm{C} 2 \mathrm{C} 12$ myoblasts from growth medium to lowserum fusion medium induces formation of multinucleated, myosin-expressing myotubes [39], and provides a quantifiable 

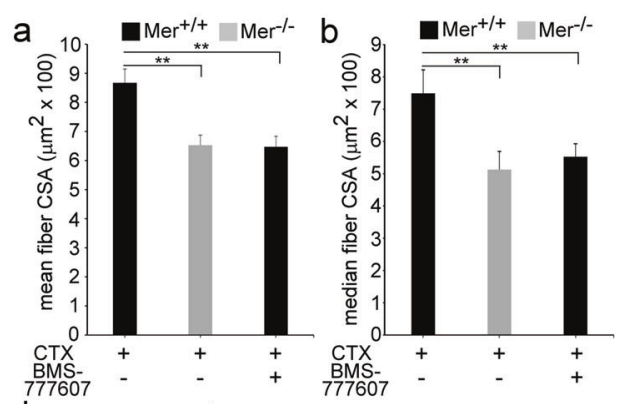

C
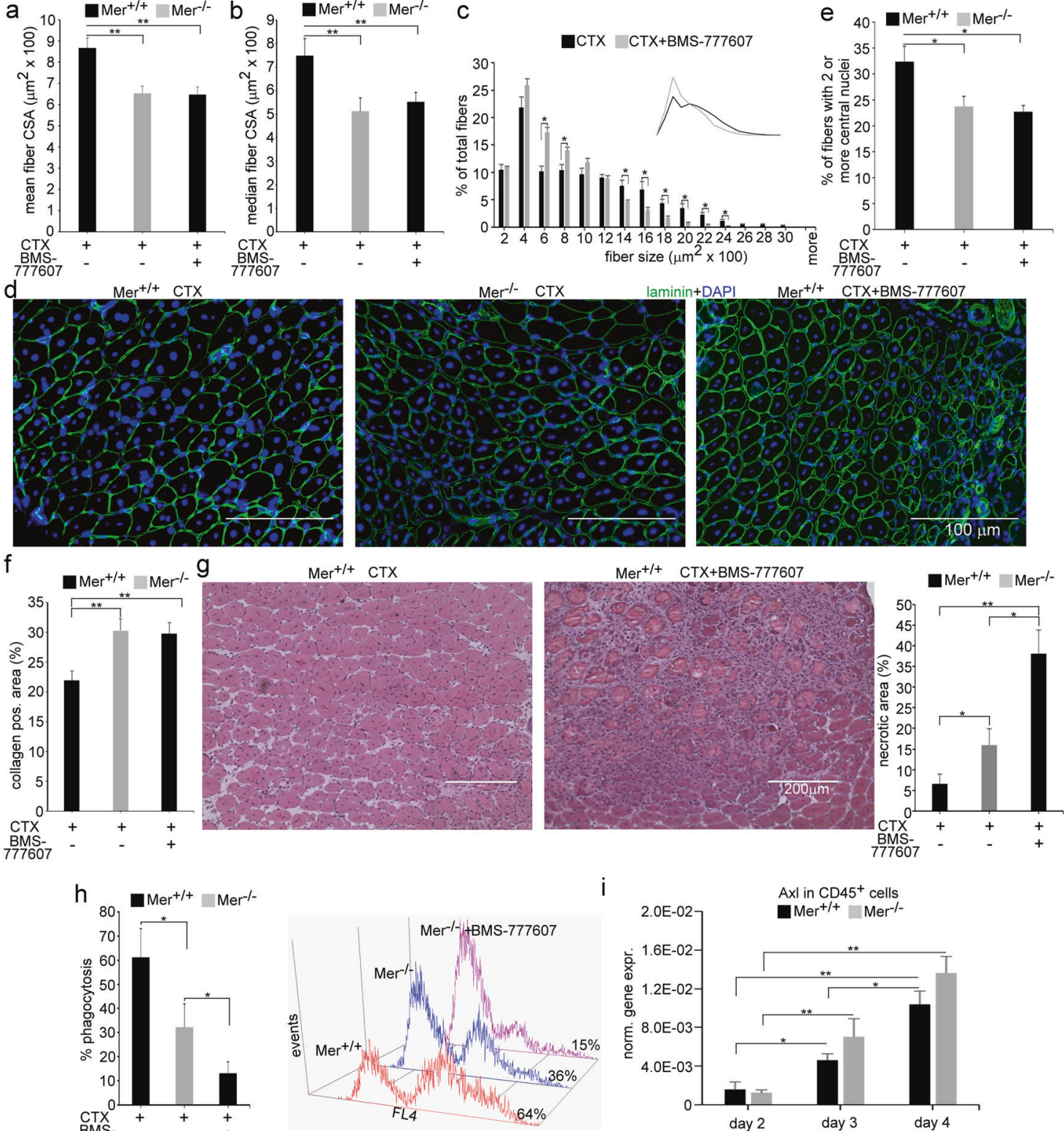

$\mathrm{Mer}^{+/+} \quad \mathrm{CTX}+\mathrm{BMS}-777607$
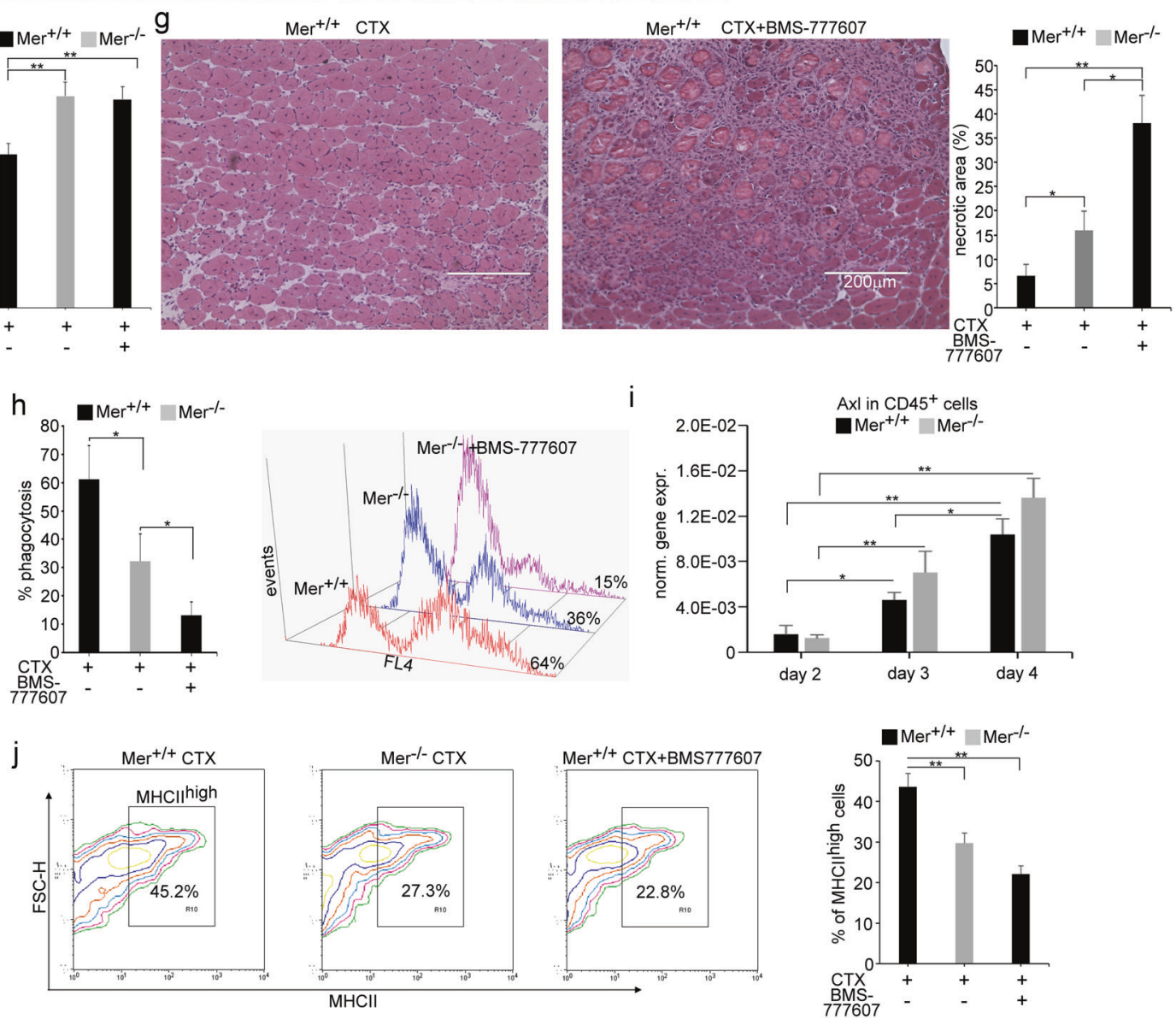

in vitro model of myogenesis [40]. We used this model to study whether TAM receptor signaling is required for the myogenesis process. Since skeletal muscle cells do not express Mer or Tyro3, we determined first the mRNA (Fig. 6a) and protein expression (Fig. 6b) levels of the three TAM kinases in the C2C12 myoblasts as well. Similar to the in vivo data, we could not detect protein expressions of Mer or Tyro3 (data not shown). Axl, however, was expressed by $\mathrm{C} 2 \mathrm{C} 12$ myoblasts (Fig. $6 \mathrm{a}$ and b) and its expression level did not alter during their differentiation. Exposure of $\mathrm{C} 2 \mathrm{C} 12$ myoblasts to BMS-777607 in growth medium led to a slower cell growth rate by the third day (Fig. 6c). The reduced growth rate, however, was not the result of a reduced cell proliferation detected by the percentage of pS10 histone H3-positive cells (Fig. 6d), rather that of an increased rate of cell death (Fig. 6e). Shifting $\mathrm{C} 2 \mathrm{C} 12$ cells to the low-serum fusion medium also resulted in an inhibition of the cell growth rate by the third day, but it was more pronounced in the inhibitor-exposed cells (Fig. 6f). The number of myoblasts did not change during the following days of 
Fig. 5 In vivo administration of the pan-TAM tyrosine kinase inhibitor BMS-777607 into wild-type mice added during the early stage of regeneration impairs muscle repair following CTX-induced injury. Muscle injury was induced by CTX as above in the tibialis anterior (TA) muscle of $\mathrm{Mer}^{+/+}$and $\mathrm{Mer}^{-/-}$mice. BMS-777607 was also injected on days 1 and 3 following CTX injection into some Mer ${ }^{+/+}$mice. TA muscles from the three types of mice were analyzed at day 10 post-CTX-induced injury. $\mathbf{a}$ Mean and $\mathbf{b}$ median myofiber cross-sectional areas of BMS777607-treated $\mathrm{Mer}^{+/+}$muscles in comparison to that found in the $\mathrm{Mer}^{+/+}$and $\mathrm{Mer}^{-/-}$muscles, $\mathbf{c}$ distribution of myofiber sizes in Mer ${ }^{+/+} \mathrm{TA}^{-}$ muscles exposed or not to BMS-777607, and d representative immunofluorescence images of laminin (green) and DAPI (blue) nuclear staining of the three types of CTX-treated muscle. Scale bars, $200 \mu \mathrm{m}$. In total, 500 or more myofibers were analyzed in each sample using Image J software $(n=6)$. e Percentage of newly formed myofibers containing two or more central nuclei in regenerating Mer ${ }^{+/+}$muscles exposed or not to BMS-777607 in comparison to that found in the $\mathrm{Mer}^{-1-}$ muscles $(n=6)$. f Quantification of the type 1 collagen-positive areas in regenerating $\mathrm{Mer}^{+/+}$muscles exposed or not to BMS-777607in comparison to that found in the Mer ${ }^{-/-}$muscles $(n=4)$. g Representative H\&Estained sections from $\mathrm{Mer}^{+/+}$muscles regenerating in the presence and absence of BMS-777607 and quantification of their necrotic areas in comparison to that found in the Mer ${ }^{-1-}$ muscles $(n=4)$. Scale bars, $100 \mu \mathrm{m}$. h Necrotic C2C12 myoblast cell phagocytic capacity of musclederived $\mathrm{Mer}^{+/+}, \mathrm{Mer}^{-/-}$, and $1 \mu \mathrm{M}$ BMS-777607-treated $\mathrm{Mer}^{-/-} \mathrm{M} \Phi$ s isolated at day 4 post-CTX-induced injury determined by flow cytometric

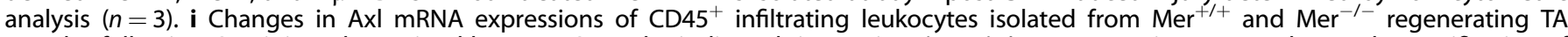
muscles following CTX injury determined by qRT-PCR at the indicated time points $(n=6)$. j Representative scatter plots and quantification of $\mathrm{MHCll}$ stained $\mathrm{F} 4 / 80^{+}$cells derived from the three types of muscle determined at day 4 following CTX-induced injury ( $n=3$ ). All data are expressed as mean or median \pm SEM. Asterisks indicate statistical significance $\left({ }^{*} P<0.05,{ }^{*} P<0.01\right.$, Student's $t$-test and ANOVA test).

differentiation in any of the cultures, but on day 6 , the number of inhibitor-treated cells started to decrease. Accordingly, on day 6 , the number of propidium iodide-labeled dead cells floating in the culture medium increased significantly in the inhibitor-treated culture (Fig. $6 \mathrm{~g}$ ), while that of the DAPI-labeled nuclei per highpower field decreased (Fig. 6h, i).

Exposure of differentiating myoblasts to BMS-777607 did not affect the expression of Axl. Neither was the differentiation of C2C12 myoblasts detected with the help of the MYHC4 expression affected until day 6, when the expression of MYHC4 in the inhibitor-treated cultures did not increase further (Fig. 6b). BMS777607 did not interfere with the myoblast fusion either (Fig. 6i, j). However, the fused myoblasts showed an impaired growth in the absence of TAM kinase signaling (Fig. 6i, k).

\section{DISCUSSION}

In the present study, the involvement of Mer in the skeletal muscle regeneration process was studied by using the cardiotoxin injury model. Previous studies have already indicated that infiltrating MФs play a key role in the orchestration of this biological process. Thus, inhibition of the MФ infiltration in CCR2 null mice [35], impaired efferocytosis due to genetic ablation of scavenger receptor class $\mathrm{BI}$ [33], or impaired $\mathrm{M} \Phi$ phenotypic change into the healing direction in the absence of the nuclear receptor PPAR [9] or the Nfix transcription factor [41], all severely delayed the regeneration process.

Mer is a member of the TAM receptor tyrosine kinase family. Genetic studies have shown that TAM signaling plays an essential role, especially in the sentinel cells of the immune system, where the principal receptors are Mer and Axl [19]. Though both receptors are involved in efferocytosis, Mer was shown to be expressed dominantly by tissue-resident macrophages or to function in tolerogenic settings, while $A x l$ was found to be expressed by inflammatory macrophages and to function in inflammatory environments [19]. In line with these observations, Axl was expressed in muscle-derived wild-type $\mathrm{CD} 45^{+}$cells from the early phase of regeneration. Mer expressions, however, were induced significantly only by day 4 , when a high percentage of infiltrating Ly6C high pro-inflammatory macrophages was already converted to Ly6C $\mathrm{C}^{\text {low }}$ healing macrophages. Interestingly, however, Mer expression was independent of Ly6C.

Previous studies have indicated that Mer contributes to maintenance of normal homeostasis in organs by promoting efferocytosis by macrophages [22] and via contributing to the initiation of the anti-inflammatory program following apoptotic cell uptake $[23,24,26]$. Though cytokine production during the early efferocytosis of damaged muscle cells by muscle tissueresident macrophages expressing Mer very likely plays a role in initiating recruitment of neutrophils and then that of the infiltrating macrophages following muscle injury, we have not found a difference in the production of MCP-1 or in the number or composition of the recruited cells in Mer null muscles.

We found, however, that Mer significantly contributed to the efferocytosis by post-injury day 4 MФs, though based on the TAM kinase inhibitory experiments, it was not the only TAM kinase receptor to do so. Consistent with this finding, we detected significantly increased necrotic tissue areas in the knockout muscle at day 10 post injury in the TA muscles, but this difference was no longer present at day 22 post-injury highlighting the role of other muscle macrophage phagocytic receptors in the dead cell clearance.

In line with the impaired efferocytosis, we could also demonstrate a delayed pro-inflammatory/healing macrophage conversion in the absence of Mer, as both the disappearance of Ly6C-positive, and the appearance of ${\mathrm{CD} 206^{+}}$or $\mathrm{MHCll}^{\text {high }}$ macrophage population, were delayed in the $\mathrm{Mer}^{-/-}$regenerating muscle. Simultaneously, we detected significantly reduced CSA in the regenerating muscles of $\mathrm{Mer}^{-1-}$ mice. Since Mer is not expressed by the skeletal muscle, the smaller CSA must be the consequence of impaired growth of newly formed fibers and/or of a slower myoblast fusion rate in the muscle as a result of the decreased growth factor production by $\mathrm{Mer}^{-1-}$ MФs. Similar was the finding, when wild-type mice were injected with BMS-777607 that inhibits both Mer and Axl signaling underlying the dominant role of macrophage Mer in this phenotype. In addition, however, we detected much longer persisting larger necrotic areas in the TA muscles of inhibitor-treated mice at day 10 post CTX-induced injury indicating a further reduced $M \Phi$ efferocytotic capacity in the absence of $M \Phi A x l$, and also a possible involvement of the muscle Axl in the myogenesis process.

Axl is known to be activated via the bridging molecule GAS6 [42] and myoblasts release GAS6 to support Axl signaling in an autocrine manner [43]. The mechanism of TAM receptor activation is unique among receptor tyrosine kinase families, requiring both a protein ligand and the lipid moiety PS [44]. When muscle cells die following injury, they can provide this PS for both the engulfing macrophages, as well as for the early proliferating and differentiating SCs, which already express Axl [45]. In addition, increasing evidence indicates that not only phagocytosis of apoptotic cells, but myoblast fusion is also PS-dependent [46]. During myoblast fusion, PS appears at the fusing cell-cell contact areas and almost exclusively only on mononucleated myoblasts in contact with other mononucleated cells or small myotubes containing only a few nuclei [46]. This asymmetric PS location will trigger Axl and provide myotube survival and growth signal always in those myotubes, which undergo continuous fusion. The interaction between PS and two PS-recognizing efferocytosis 
a

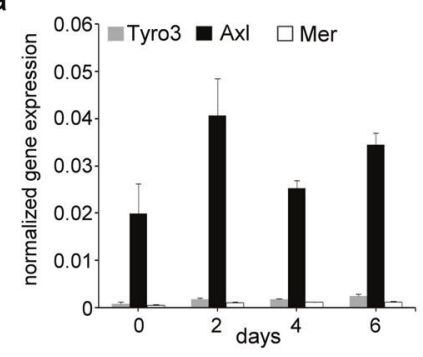

b

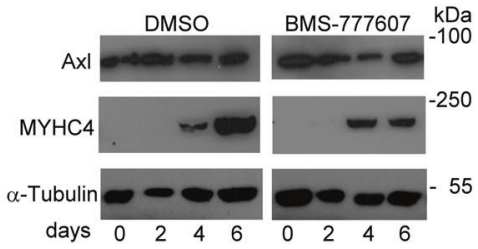

C

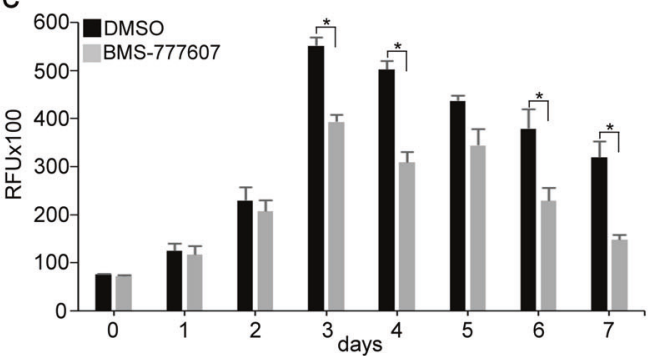

d

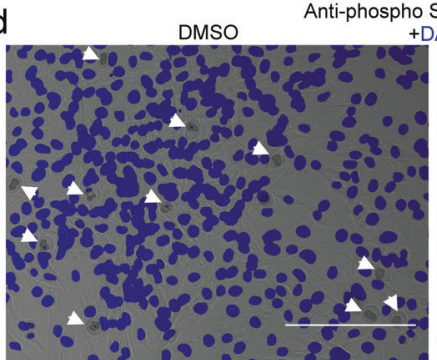

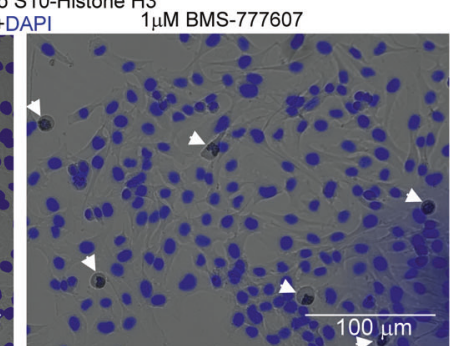

e
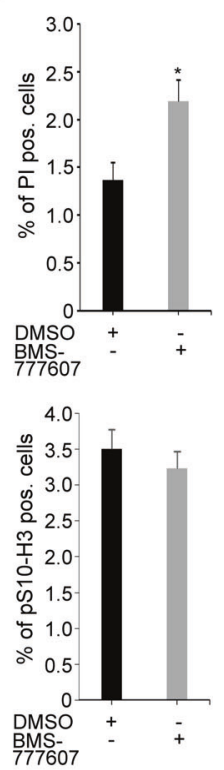

g
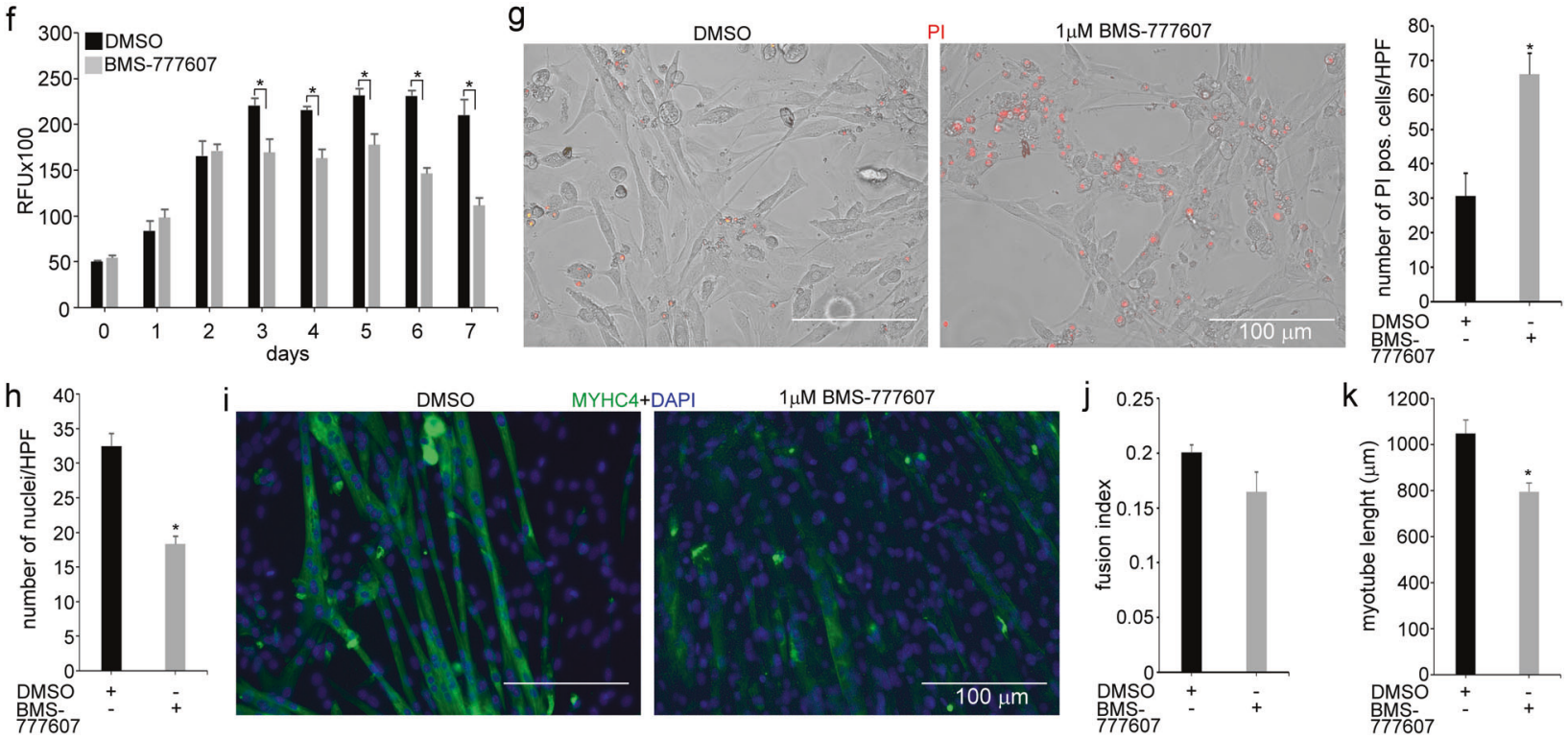

k 1200 -

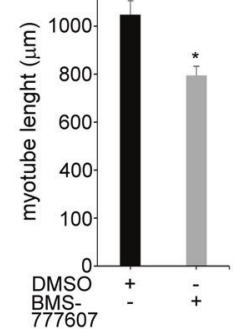

Fig. 6 In vitro administration of the pan-TAM tyrosine kinase inhibitor BMS-777607 impairs myogenesis of C2C12 myoblast cells. a mRNA expression levels of Tyro3, Axl, and Mer during the differentiation of C2C12 myoblast cells determined by qRT-PCR. $\mathbf{b}$ Protein expression levels of Axl and myosin heavy chain 4 (MYHC4) in differentiating C2C12 myoblasts in the presence or absence of $1 \mu \mathrm{M}$ BMS777607 determined by Western blot analysis. $\alpha$-Tubulin was used as a loading control. One representative blot of three is shown. c Alterations in the number of viable $\mathrm{C} 2 \mathrm{C} 12$ cells grown in growth medium in the presence or absence of $1 \mu \mathrm{M}$ BMS-777607 determined by PrestoBlue staining. d Percent of cells in G2/M phase grown in growth medium in the presence or absence of $1 \mu \mathrm{M}$ BMS-777607 as indicated by antiphospho-histone H3 (Ser10) and DAPI co-staining (at least 20 HPF were analyzed). Arrows point to the anti-phospho-histone H3 positive nuclei. e Percent of PI-positive cells grown in growth medium in the presence or absence of $1 \mu \mathrm{M}$ BMS-777607. $\mathbf{f}$ Alterations in the number of viable $\mathrm{C} 2 \mathrm{C} 12$ cells grown in differentiation medium in the presence or absence of $1 \mu \mathrm{M}$ BMS-777607 determined by PrestoBlue staining. BMS777607 was added when the medium was changed to differentiation medium. $\mathbf{g}$ Representative light microscopic images of C2C12 myoblasts differentiated for 6 days in the absence or presence of $1 \mu \mathrm{M}$ BMS-777607 after staining dead cells with propidium iodide and quantification of propidium iodide-positive nuclei per high-power field (at least $20 \mathrm{HPF}$ were analyzed). $\mathbf{h}$ Number of nuclei per high-power field of C2C12 cells differentiated for 6 days in the absence or presence of $1 \mu \mathrm{M}$ BMS-777607. i Representative fluorescent microscopic images of C2C12 myoblasts differentiated for 6 days in the absence or presence of $1 \mu \mathrm{M}$ BMS-777607. MYHC4 was visualized by using anti-MYHC4 antibody (green) and nuclei by DAPI (blue). j Fusion index of C2C12 cells differentiated for 6 days in the absence or presence of $1 \mu M$ BMS-777607. $\mathbf{k}$ The length of myotubes generated from C2C12 myoblasts differentiated for 6 days in the absence or presence of $1 \mu \mathrm{M}$ BMS-777607. All the data are expressed as mean \pm SEM of three independent experiments. Asterisks indicate statistical significance $\left({ }^{*} P<0.05\right.$, Student's $t$-test). Scale bars, $100 \mu \mathrm{m}$.

receptors (brain-specific angiogenesis inhibitor 1 (BAI1) and stabilin-2) on the surface of myoblasts has already been reported to be a prerequisite for cell fusion during muscle fiber formation $[38$, 47]. Our data identify Axl, as a third PS-dependent efferocytosis receptor to be also required for proper myogenesis, but acting as a myotube growth and survival receptor. The potential involvement of GAS6 and Axl in the muscle development process is also supported by a recent observation that the 
dominant phenotype of GAS6/Axl double-knock out mice is a significantly reduced skeletal muscle mass [48]. Altogether, our data demonstrate that intact TAM kinase receptor signaling is required for the proper muscle regeneration process both in the muscle-derived macrophages and in the myoblasts.

\section{REFERENCES}

1. Deconinck, N \& Dan, B Pathophysiology of Duchenne muscular dystrophy: current hypotheses. Ped Neurol 36, 1-7 (2007).

2. Rigamonti, E, Touvier, T, Clementi, E, Manfredi, AA, Brunelli, S \& Rovere-Querini, $P$ Requirement of inducible nitric oxide synthase for skeletal muscle regeneration after acute damage. J Immunol 190, 1767-77 (2013).

3. Vezzoli, M, Castellani, P, Corna, G, Castiglioni, A, Bosurgi, L \& Monno, A et al. Highmobility group box 1 release and redox regulation accompany regeneration and remodeling of skeletal muscle. Antioxid Redox Signal 15, 2161-74 (2011).

4. Baghdadi, MB \& Tajbakhsh, $S$ Regulation and phylogeny of skeletal muscle regeneration. Dev Biol 433, 200-9 (2018).

5. Tidball, JG \& Villalta, SA Regulatory interactions between muscle and the immune system during muscle regeneration. Am J Physiol Regul Integr Comp Physiol 298, R1173-R1187 (2010).

6. Arnold, L, Henry, A, Poron, F, Baba-Amer, Y, van Rooijen, N \& Plonquet, A et al Inflammatory monocytes recruited after skeletal muscle injury switch into antiinflammatory macrophages to support myogenesis. J Exp Med 204, 1057-69 (2007).

7. Saclier, M, Yacoub-Youssef, H, Mackey, AL, Arnold, L, Ardjoune, H \& Magnan, M et al. Differentially activated macrophages orchestrate myogenic precursor cell fate during human skeletal muscle regeneration. Stem Cells 31, 384-96 (2013).

8. Bosurgi, L, Corna, G, Vezzoli, M, Touvier, T, Cossu, G \& Manfredi, AA et al. Transplanted mesoangioblasts require macrophage IL-10 for survival in a mouse model of muscle injury. J Immunol 188, 6267-77 (2012).

9. Varga, T, Mounier, R, Patsalos, A, Gogolák, P, Peloquin, M \& Horvath, A et al. Macrophage PPAR $\gamma$, a lipid activated transcription factor controls the growth factor GDF3 and skeletal muscle regeneration. Immunity 45, 1038-51 (2016).

10. Chazaud, B Inflammation and skeletal muscle regeneration: leave it to the macrophages. Trends Immunol. 6, 481-92 (2020).

11. von Maltzahn, J, Jones, AE, Parks, RJ \& Rudnicki, MA Pax7 is critical for the normal function of satellite cells in adult skeletal muscle. Proc Natl Acad Sci USA 110, 16474-9 (2013)

12. Bentzinger, CF, Wang, $Y X$ \& Rudnicki, MA Building muscle: molecular regulation of myogenesis. Cold Spring Harb Perspect Biol 4, a008342 (2012).

13. Kuang, S, Chargé, SB, Seale, $P$, Huh, M \& Rudnicki, MA Distinct roles for Pax7 and Pax3 in adult regenerative myogenesis. J Cell Biol 172, 103-13 (2006).

14. Grabiec, K, Tokarska, J, Milewska, M, Błaszczyk, M, Gajewska, M \& GrzelkowskaKowalczyk, K Interleukin-1beta stimulates early myogenesis of mouse $\mathrm{C} 2 \mathrm{C} 12$ myoblasts: the impact on myogenic regulatory factors, extracellular matrix components, IGF binding proteins and protein kinases. Pol J Vet Sci 16, 255-64 (2013).

15. Deng, B, Wehling-Henricks, M, Villalta, SA, Wang, Y \& Tidball, JG IL-10 triggers changes in macrophage phenotype that promote muscle growth and regeneration. J Immunol 189, 3669-80 (2012).

16. Manning, G, Whyte, DB, Martinez, R, Hunter, $T$ \& Sudarsanam, $S$ The protein kinase complement of the human genome. Science 298, 1912-34 (2002).

17. Linger, RM, Keating, AK, Earp, HS \& Graham, DK TAM receptor tyrosine kinases: biologic functions, signaling, and potential therapeutic targeting in human cancer. Adv Cancer Res 100, 35-83 (2008).

18. McShane, L, Tabas, I, Lemke, G, Kurowska-Stolarska, M \& Maffia, P TAM receptors in cardiovascular disease. Cardiovasc Res 115, 1286-95 (2019).

19. Lemke, G Biology of the TAM receptors. Cold Spring Harb Perspect Biol 5, a009076 (2013).

20. Graham, DK, Dawson, TL, Mullaney, DL, Snodgrass, HR \& Earp, HS Cloning and mRNA expression analysis of a novel human protooncogene, c-mer. Cell Growth Differ 5, 647-57 (1994).

21. Zizzo, G, Hilliard, BA, Monestier, M \& Cohen, PL Efficient clearance of early apoptotic cells by human macrophages requires $\mathrm{M} 2 \mathrm{C}$ polarization and Mer induction. J Immunol 189, 3508-20 (2012).

22. Dransfield, I, Zagórska, A, Lew, ED, Michail, K \& Lemke, G Mer receptor tyrosine kinase mediates both tethering and phagocytosis of apoptotic cells. Cell Death Dis 6, e1646-e1646 (2015).

23. Camenisch, TD, Koller, BH, Earp, HS \& Matsushima, GK A novel receptor tyrosine kinase, Mer, inhibits TNF-a production and lipopolysaccharide-induced endotoxic shock. J Immunol 162, 3498-503 (1999).

24. Tibrewal, N, Wu, Y, D'mello, V, Akakura, R, George, TC \& Varnum, B et al. Autophosphorylation docking site Tyr-867 in Mer receptor tyrosine kinase allows for dissociation of multiple signaling pathways for phagocytosis of apoptotic cells and down-modulation of lipopolysaccharide-inducible NF-KB transcriptional activation. J Biol Chem 283, 3618-27 (2008)

25. Eken, C, Martin, PJ, Sadallah, S, Treves, S, Schaller, M \& Schifferli, JA Ectosomes released by polymorphonuclear neutrophils induce a Mer-dependent antiinflammatory pathway in macrophages. J Biol Chem 285, 39914-21 (2010).

26. Cai, B, Thorp, EB, Doran, AC, Subramanian, M, Sansbury, BE \& Lin, CS et al. Mer cleavage limits proresolving mediator biosynthesis and exacerbates tissue inflammation. Proc Natl Acad Sci USA 13, 6526-31 (2016).

27. Triantafyllou, E, Pop, OT, Possamai, LA, Wilhelm, A, Liaskou, E \& Singanayagam, A et al. Mer expressing hepatic macrophages promote the resolution of inflammation in acute liver failure. Gut 67, 333-47 (2018).

28. Linton, MF, Babaev, VR, Huang, J, Linton, EF, Tao, H \& Yancey, PG Macrophage apoptosis and efferocytosis in the pathogenesis of atherosclerosis. Circ $J \mathbf{8 0}$ 2259-68 (2016).

29. Ait-Oufella, H, Pouresmail, V, Simon, T, Blanc-Brude, O, Kinugawa, K \& Merval, R et al. Defective mer receptor tyrosine kinase signaling in bone marrow cells promotes apoptotic cell accumulation and accelerates atherosclerosis. Arterioscler Thromb Vasc Biol 28, 1429-31 (2008).

30. DeBerge, M, Yeap, XY, Dehn, S, Zhang, S, Grigoryeva, L \& Misener, S et al. MerTK cleavage on resident cardiac macrophages compromises repair after myocardial ischemia reperfusion injury. Circ Res 121, 930-40 (2017).

31. Patsalos, A, Tzerpos, P, Halasz, L, Nagy, G, Pap, A \& Giannakis, N et al. The $\mathrm{BACH} 1-\mathrm{HMOX} 1$ regulatory axis is indispensable for proper macrophage subtype specification and skeletal muscle regeneration. J Immunol 203, 1532-47 (2019).

32. Budai, Z, Ujlaky-Nagy, L, Kis, GN, Antal, M, Bankó, C \& Bacsó, Z et al. Macrophages engulf apoptotic and primary necrotic thymocytes through similar phosphatidylserine-dependent mechanisms. FEBS Open Bio 9, 446-56 (2019).

33. Zhang, J, Qu, C, Li, T, Cui, W, Wang, X \& Du, J Phagocytosis mediated by scavenger receptor class $\mathrm{BI}$ promotes macrophage transition during skeletal muscle regeneration. J Biol Chem 294, 15672-85 (2019).

34. Seko, D, Fujita, R, Kitajima, Y, Nakamura, K, Imai, Y \& Ono, Y Estrogen receptor $\beta$ controls muscle growth and regeneration in young female mice. Stem Cell Rep 15, 577-86 (2020).

35. Martinez, CO, McHale, MJ, Wells, JT, Ochoa, O, Michalek, JE \& McManus, LM et al. Regulation of skeletal muscle regeneration by CCR2-activating chemokines is directly related to macrophage recruitment. Am J Physiol Regul Integr Comp Physiol 299, R832-842 (2010).

36. Chávez-Galán, L, Olleros, ML, Vesin, D \& Garcia, I Much more than M1 and M2 macrophages, there are also CD169+ and TCR+ macrophages. Front Immunol 6 , 263 (2015).

37. Panduro, $M$, Benoist, $C$ \& Mathis, D Treg cells limit IFN- $\gamma$ production to control macrophage accrual and phenotype during skeletal muscle regeneration. Proc Natl Acad Sci USA 115, E2585-E2593 (2018).

38. Zagórska, A, Través, PG, Lew, ED, Dransfield, I \& Lemke, G Diversification of TAM receptor tyrosine kinase function. Nat Immunol 15, 920-8 (2014).

39. Yaffe, D \& Saxel, O Serial passaging and differentiation of myogenic cells isolated from dystrophic mouse muscle. Nature 270, 725-7 (1977).

40. Hochreiter-Hufford, AE, Lee, CS, Kinchen, JM, Sokolowski, JD, Arandjelovic, S \& Call, JA et al. Phosphatidylserine receptor BAl1 and apoptotic cells as new promoters of myoblast fusion. Nature 497, 263-7 (2013).

41. Saclier, M, Lapi, M, Bonfanti, C, Rossi, G, Antonini, S \& Messina, G The transcription factor Nfix requires RhoA-ROCK1 dependent phagocytosis to mediate macrophage skewing during skeletal muscle regeneration. Cells 9, 708 (2020).

42. Tsou, WI, Nguyen, KQ, Calarese, DA, Garforth, SJ, Antes, AL \& Smirnov, SV et al. Receptor tyrosine kinases, TYRO3, AXL, and MER, demonstrate distinct patterns and complex regulation of ligand-induced activation. J Biol Chem 289, 25750-63 (2014).

43. Chikazawa, M, Shimizu, M, Yamauchi, Y \& Sato, R Bridging molecules are secreted from the skeletal muscle and potentially regulate muscle differentiation. Biochem Biophys Res Commun 522, 113-20 (2020).

44. Stitt, TN, Conn, G, Gore, M, Lai, C, Bruno, J \& Radziejewski, C et al. The anticoagulation factor protein $\mathrm{S}$ and its relative, Gas6, are ligands for the Tyro 3/Axl family of receptor tyrosine kinases. Cell 80, 661-70 (1995).

45. Sinha, M, Jang, YC, Oh, J, Khong, D, Wu, EY \& Manohar, R et al. Restoring systemic GDF11 levels reverses age-related dysfunction in mouse skeletal muscle. Science 344, 649-52 (2014).

46. Van den Eijnde, SM, van den Hoff, MJ, Reutelingsperger, CP, van Heerde, WL, Henfling, ME \& Vermeij-Keers, $C$ et al. Transient expression of phosphatidylserine at cell-cell contact areas is required for myotube formation. J Cell Sci 114, 3631-42 (2001).

47. Park, SY, Yun, Y, Lim, JS, Kim, MJ, Kim, SY \& Kim, JE et al. Stabilin-2 modulates the efficiency of myoblast fusion during myogenic differentiation and muscle regeneration. Nat Commun 7, 1-15 (2016). 
12

48. Olsen, ZE, Mervis, MJ, Matsumara, MC, Hirschi-Budge, KM, Arroyo, JA \& Reynolds, $\mathrm{PR}$ et al. Gas6-Axl double knockout in mice decreases skeletal muscle mass despite elevated anabolic intracellular signaling. FASEB J 37, S5 (2020). (Meeting abstract).

\section{ACKNOWLEDGEMENTS}

The authors thank Dr. Andreas Patsalos for critical reading of the paper. The excellent technical assistance of Evelin Erdős and Lívia Beke is gratefully acknowledged.

\section{AUTHOR CONTRIBUTIONS}

N.A. performed most of the experiments and analyzed the data, Zs.B. helped to set up the detection of myoblast fusion both in vivo and in vitro, Zs.S. supervised the experiments, prepared the figures and wrote the first version of the paper, while Zs. Sz. designed the experiments, analyzed the data, wrote the final version of the paper and was responsible for funding acquisition.

\section{FUNDING}

This research was funded by European Union project titled: Institutional Developments for Intelligent Specialization program (grant number: EFOP-3.6.1-16-201600022 "Debrecen Venture Catapult Program"), the National Research, Development and Innovation Office (124244), and by the GINOP2.3.2-15-2016-00006 project (cofinanced by the European Union and the European Regional Development Fund). Zsolt Sarang was a recipient of Lajos Szodoray fellowship given by the University of Debrecen.

\section{ETHICS STATEMENT}

This study did not require ethical approval.
COMPETING INTERESTS

The authors declare no competing interests.

\section{ADDITIONAL INFORMATION}

Supplementary information The online version contains supplementary material available at https://doi.org/10.1038/s41419-021-03892-5.

Correspondence and requests for materials should be addressed to Z.S.

Reprints and permission information is available at http://www.nature.com/ reprints

Publisher's note Springer Nature remains neutral with regard to jurisdictional claims in published maps and institutional affiliations.

Open Access This article is licensed under a Creative Commons Attribution 4.0 International License, which permits use, sharing, adaptation, distribution and reproduction in any medium or format, as long as you give appropriate credit to the original author(s) and the source, provide a link to the Creative Commons license, and indicate if changes were made. The images or other third party material in this article are included in the article's Creative Commons license, unless indicated otherwise in a credit line to the material. If material is not included in the article's Creative Commons license and your intended use is not permitted by statutory regulation or exceeds the permitted use, you will need to obtain permission directly from the copyright holder. To view a copy of this license, visit http://creativecommons. org/licenses/by/4.0/

(c) The Author(s) 2021 